Pacific Northwest

National Laboratory

Operated by Battelle for the

U.S. Department of Energy

\section{Initial Assessments for the T and TX-TY Tank Farms Field Investigation Report (FIR): Numerical Simulations}

\author{
Z. F. Zhang \\ V. L. Freedman \\ S. R. Waichler
}

September 2004 


\section{DISCLAIMER}

This report was prepared as an account of work sponsored by an agency of the United States Government. Neither the United States Government nor any agency thereof, nor Battelle Memorial Institute, nor any of their employees, makes any warranty, express or implied, or assumes any legal liability or responsibility for the accuracy, completeness, or usefulness of any information, apparatus, product, or process disclosed, or represents that its use would not infringe privately owned rights. Reference herein to any specific commercial product, process, or service by trade name, trademark, manufacturer, or otherwise does not necessarily constitute or imply its endorsement, recommendation, or favoring by the United States Government or any agency thereof, or Battelle Memorial Institute. The views and opinions of authors expressed herein do not necessarily state or reflect those of the United States Government or any agency thereof.

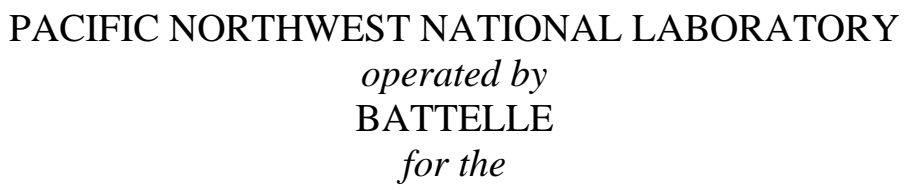

UNITED STATES DEPARTMENT OF ENERGY under Contract DE-ACO6-76RLO183O

Printed in the United States of America

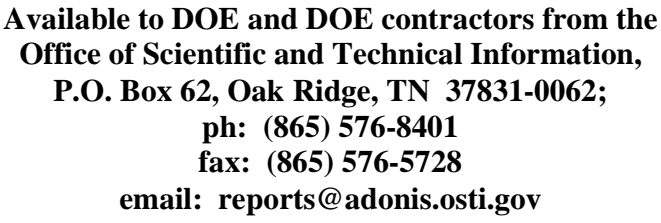

Available to the public from the National Technical Information Service, U.S. Department of Commerce, 5285 Port Royal Rd., Springfield, VA 22161 ph: (800) 553-6847 fax: $(703) 605-6900$ email: orders@ntis.fedworld.gov online ordering: http://www.ntis.gov/ordering.htm 


\title{
2004 Initial Assessments for the T and TX-TY Tank Farms Field Investigation Report (FIR): Numerical Simulations
}

\author{
Z. F. Zhang \\ V. L. Freedman \\ S. R. Waichler
}

September 2004

\author{
Prepared for \\ the U.S. Department of Energy \\ under Contract DE-AC06-76RL01830
}

Pacific Northwest National Laboratory

Richland, WA 99352 


\section{Summary}

In support of CH2M HILL Hanford Group, Inc.'s (CHG) preparation of a Field Investigative Report (FIR) for the Hanford Site Single-Shell Tank Waste Management Area (WMA) T and TX-TY, a suite of numerical simulations of flow and solute transport was executed using the STOMP code to predict the performance of surface barriers for reducing long-term risks from potential groundwater contamination at the T and TX-TY WMA. The scope and parametric data for these simulations were defined by a modeling data package provided by CHG. This report documents the simulations involving 2-D cross sections through the T Tank Farm (T-106, T-105, and T-104) and the TX-TY Tank Farms (TX-105, TX106, TX-107, and TX-108). Eight cases were carried out for the cross sections to simulate the effects of interim barrier, waterline leak, inventory distribution, and surface recharge on water flow and the transport of long-lived radionuclides (i.e., technecium-99 and uranium) and chemicals (i.e., nitrate and chromium). Fluid flow within the vadose zone is described by Richards' equation, whereas the contaminant transport is described by the conventional advective-dispersive transport equation with an equilibrium linear sorption coefficient $\left(\mathrm{K}_{\mathrm{d}}\right)$ formulation.

For simulations with barriers, it was assumed that an interim barrier is in place by the year 2010 . It was also assumed that, for all simulations, as part of tank farm closure, a closure barrier was in place by the year 2040. Placing a barrier is expected to significantly reduce infiltration of meteoric water and therefore arrival of contaminants at the water table. The modeling considers the estimated inventories of contaminants within the vadose zone and calculates the associated risk. It assumes that no tanks will leak in the future. Initial conditions for pressure head (and moisture) are established by allowing the vadose zone to equilibrate with an infiltration rate representative of natural infiltration for tank farm conditions. The data on infiltration rates with and without barriers are included in the discussion. Initial conditions for contaminant concentration are provided as part of inventory estimates for uranium, technetium-99, nitrate, and chromium. For moisture flow modeling, Neumann boundary conditions are prescribed at the surface with the flux equal to the recharge rate estimate. For transport modeling, a zero flux boundary is prescribed at the surface for uranium, technetium-99, nitrate, and chromium. The western and eastern boundaries are assigned no-flux boundaries for both flow and transport. The water table boundary is prescribed by water table elevations and the unconfined aquifer hydraulic gradient. No-flux boundaries are used for the lower boundary. Numerical results were obtained for compliance at the WMA boundary, 200 Areas boundary, exclusion boundary beyond the 200 Areas, and the Columbia River (DOE-RL 2000). Streamtube/analytical models were used to route computed contaminant concentrations at the water table to the downstream compliance points.

After the interim barrier was applied at 2010, saturation results indicate the soil desaturates gradually. The difference in saturation of the soil with and without the interim barrier was the largest at 2040, the time the closure barrier was applied. After this, the difference in saturation in the two cases became smaller with time. Generally, the solutes broke though faster if there was a waterline leak. A relatively small five-day leak (Case 4) had little effect on the peak concentration, while a large 20-yr leak (Case 3) increased the peak concentration significantly and reduced the solute travel in the vadose zone. The distribution of the inventory, either uniform or nonuniform, has little effect on peak arrival time; the peak concentrations of the conservative solutes varied by -6.9 to $0.2 \%$ for the $\mathrm{T}$ tank farm and by 11 to $49.4 \%$ for the TX tank farm. The reduction of the meteoric recharge before the barrier was applied led to less soil saturation, as expected, and thus longer solute travel time in the vadose zone and smaller peak 
fenceline concentration. The effect on soil saturation lasted for about another 50 years after the barrier was applied at 2050. However, the reduced recharge rate affected the breakthough curve through the end of the simulation. The fenceline concentrations at the year 3000 were always higher for cases with reduced natural recharge than for those of the base case, which indicates that the fundamental impact of the reduced natural recharge is a smoothing of the breakthrough concentrations (lower peak concentration but higher tail concentration) at the compliance points. 


\section{Acronyms}

ARH

ASCII

bgs

BMI

BTCs

CA

CFEST

$\mathrm{CHG}$

CR

DOE

FIR

GIS

IA

ICM

ILAW

MDP

NUREG

ORP

PNNL

PNWD

RCRA

RPP

SGM

SPLIB

SST

STOMP

TPA

WHC

WMA
Atlantic Richfield Hanford Comp

American Standard Code for Information Interchange

below ground surface

Battelle Memorial Institute

Break Through Curves

Composite Analysis

Coupled Fluid, Energy, and Solute Transport

CH2M HILL Hanford Group, Inc.

Configuration report

U.S. Department of Energy

Field Investigation Report

Geographic Information System

initial assessment

interim corrective measures

Immobilized Low-Activity Waste

Modeling Data Package

U.S. Nuclear Regulatory Commission regulation / Nuclear Regulatory Guide

Office of River Protection, U.S. Department of Energy

Pacific Northwest National Laboratory

Pacific Northwest Division

Resource Conservation and Recovery Act

River Protection Project

Site-Wide Groundwater Model

A Library of Iterative Methods for Sparse Linear Systems

Single-Shell Tank

A flow simulator for Subsurface Transport Over Multiple Phases

The Tri-Party Agreement

Westinghouse Hanford Company

Waste Management Area 


\section{Table of Contents}

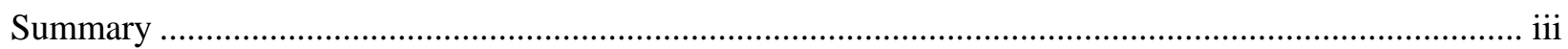

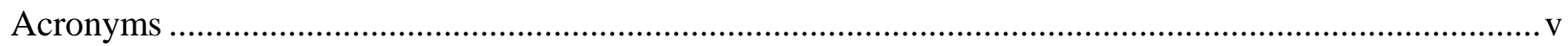

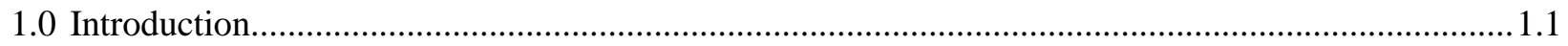

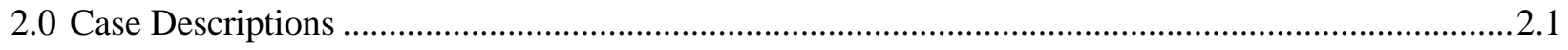

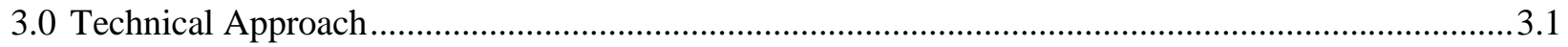

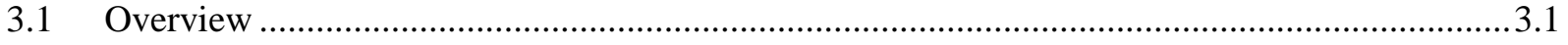

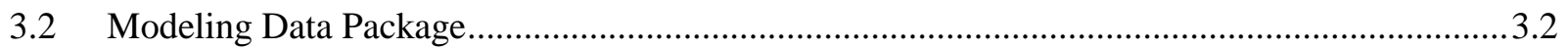

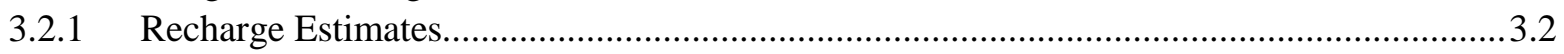

3.2.2 Vadose Zone Flow and Transport Properties ................................................................. 3.3

1.1.1 Stochastic Model for Macroscopic Anisotropy …...............................................................

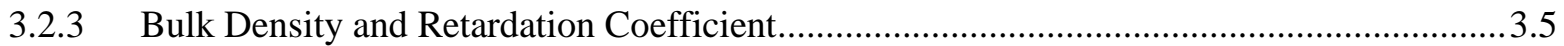

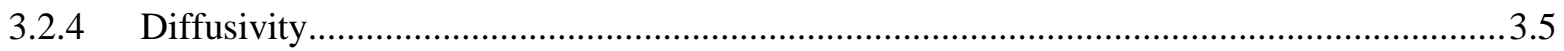

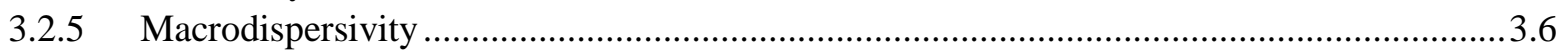

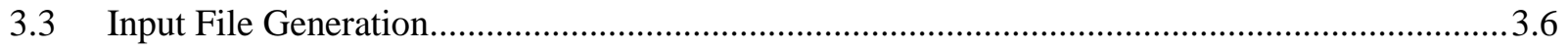

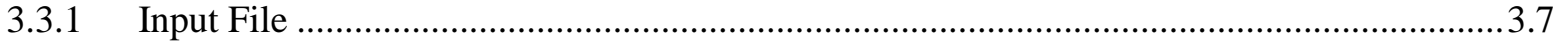

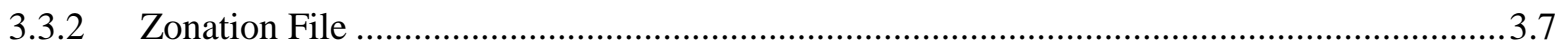

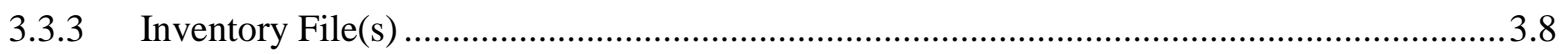

3.3.4 Two-Dimensional Cross-Section Concentrations...........................................................11

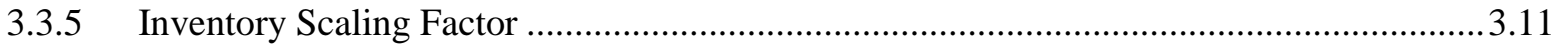

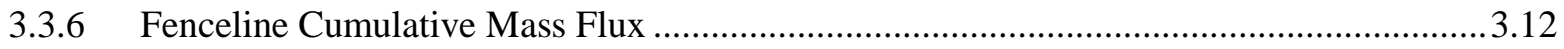

3.3.7 Dimensional Scaling Factor and Fenceline Concentrations ........................................... 3.12

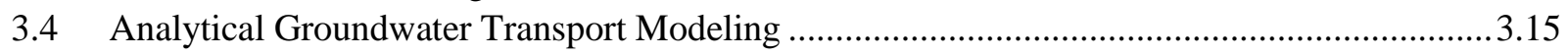

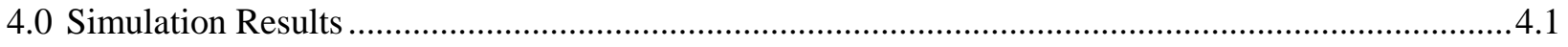

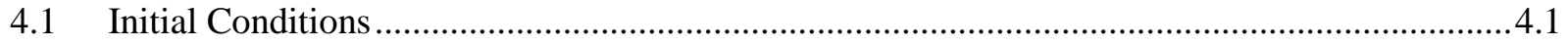

4.2 Base Case (No-Action Alternative) ............................................................................... 4.10

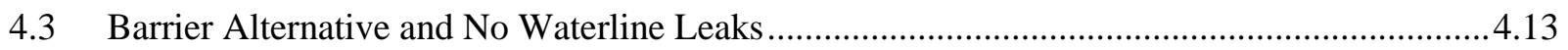

4.4 Waterline Leak and No Interim Barrier............................................................................. 4.16

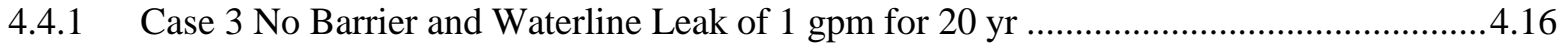

4.4.2 Case 4 No Barrier and 200,000 gal Waterline Leak ........................................................17

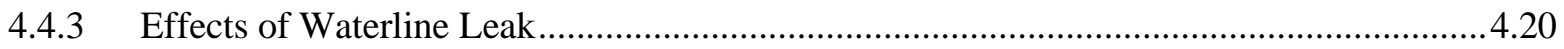

4.5 No Interim Barrier and Nonuniform Inventory Distribution.............................................4.21

4.6 Base Case with Reduced Meteoric Recharge ..................................................................22

4.6.1 Case 6, Base Case with 50 mm/yr Meteoric Recharge ......................................................22

4.6.2 Case 7 Base Case with 30 mm/yr Meteoric Recharge ......................................................23

4.6.3 Case 8, Base Case with $10 \mathrm{~mm} / \mathrm{yr}$ Meteoric Recharge.......................................................24

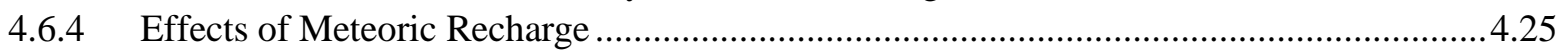

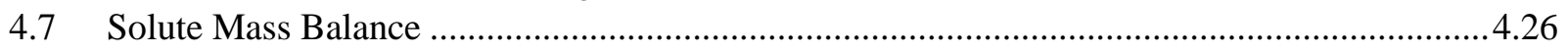

5.0 Numerical Groundwater Transport Modeling Results................................................................. 5.1

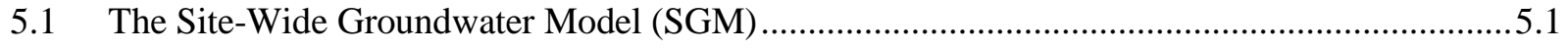

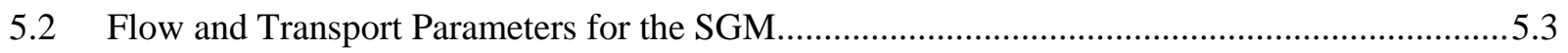




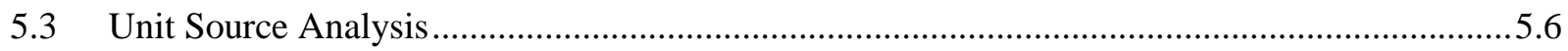

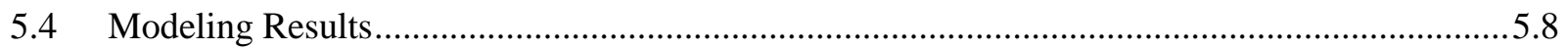

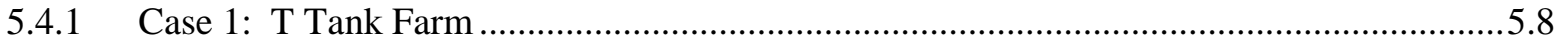

5.4.2 Case 1: TX Tank Farm .............................................................................................

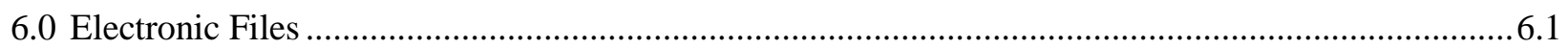

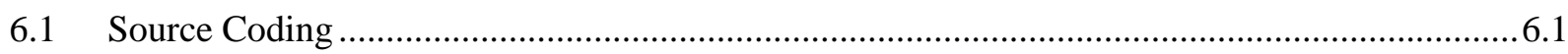

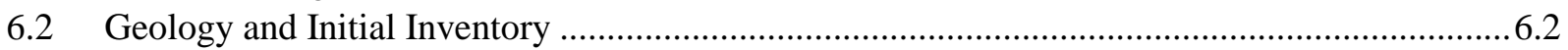

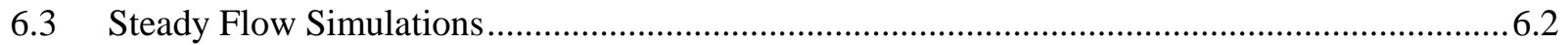

6.4 Coupled Vadose Zone and Unconfined Aquifer Modeling....................................................... 6.2

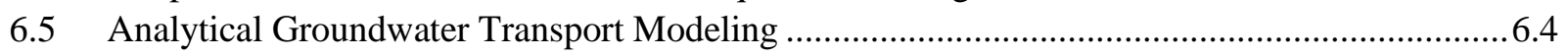

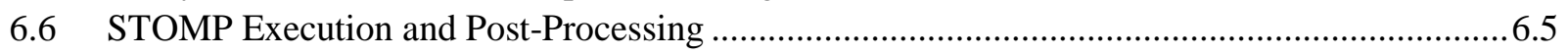

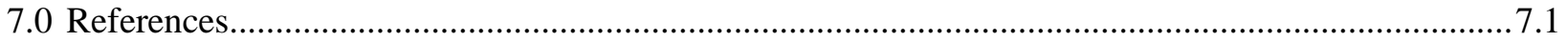




\section{Figures}

3.1 Rock/Soil Zonation for Cross Section Through T-104, T-105, and T-106....................................

3.2 Rock/Soil Zonation for Cross section Through TX-105, TX-106, TX-107, and TX-108 ................7.7

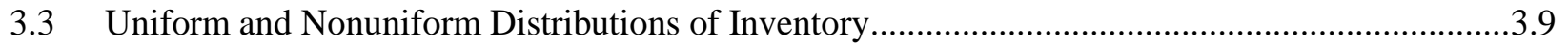

3.4 Converting a 3-D Volumetric Inventory to an Inventory of a 2-D Slice ........................................ 3.9

3.5 Fenceline Aqueous Concentration Perpendicular to Flow Direction ............................................13

3.6a Comparison of BTCs of Tc-99 Simulated with 2- and 3-D .......................................................14

$3.6 \mathrm{~b}$ Comparison of BTCs of U-238 with $\mathrm{K}_{\mathrm{d}}=0.03 \mathrm{~mL} / \mathrm{g}$ Simulated with 2- and 3-D ......................3.14

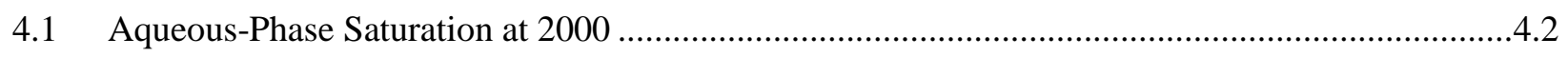

4.2 Aqueous-Phase Tc-99 Concentration at 2000 if Inventory Assigned as Uniform Distribution.......4.3

4.3 Aqueous-Phase U-238 Concentration at 2000 if Inventory Assigned as Uniform Distribution ......4.4

4.4 Aqueous-Phase $\mathrm{NO}_{3}$ Concentration at 2000 if Inventory Assigned as Uniform Distribution .........4.5

4.5 Aqueous-Phase Cr Concentration at 2000 if Inventory Assigned as Uniform Distribution ............4.6

4.6 Aqueous-Phase Tc-99 Concentration at 2000 if Inventory Assigned as Nonuniform Distribution.4.7

4.7 Aqueous-Phase U-238 Concentration at 2000 if Inventory Assigned as Nonuniform Distribution 4.8

4.8 Aqueous-Phase $\mathrm{NO}_{3}$ Concentration at 2000 if Inventory Assigned as Nonuniform Distribution ...4.9

4.9 Aqueous-Phase Cr Concentration at 2000 if Inventory Assigned as Nonuniform Distribution ....4.10

4.10 Aqueous-Phase Saturation at 2040 (100 mm/yr) for Cross Section T-104, -105, -106 ...............4.11

4.11 Aqueous-Phase Saturation at $2540(0.1 \mathrm{~mm} / \mathrm{yr})$ for Cross Section T-104, -105, -106 ................4.12

4.12 Aqueous-Phase Saturation at 3000 (3.5 mm/yr) for Cross Section T-104, -105, -106 ................4.12

4.13 Effects of the Interim Cover on the Mean Saturation of the T Tank Farm ..................................4.15

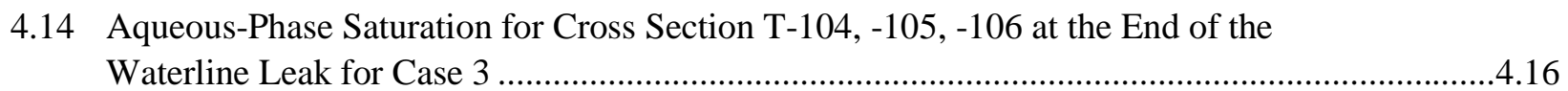

4.15 Variation of Water Flux at the Groundwater Table for Case 3 Due to the Pipeline Leak .............4.17

4.16 Aqueous-Phase Saturation for Cross Section T-104, -105, -106 at the End of the Waterline Leak for Case 4 .............................................................................................19

4.17 Effects of the Waterline Leaks on the Mean Saturation of T Tank Farm ....................................4.20

4.18 Effects of Waterline Leaks on Tc-99 Concentration at the Fenceline of T Tank Farm................4.20

4.19 Effects of Reduced Meteoric Recharge on the Mean Saturation of T Tank Farm........................4.25

4.20 Effect of Reduced Meteoric Recharge on Tc-99 Concentration at Fence Line of T Tank Farm...4.25

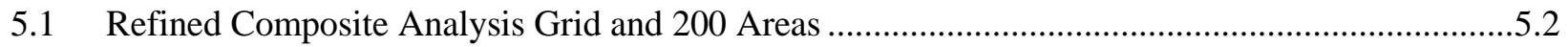

5.2 New Interpretation of the Basalt Outcrop Locations for Post-Hanford Flow Conditions ...............5.3

5.3 Map of SGM Hydrogeologic Units Containing Water Table in March 1999................................5.4

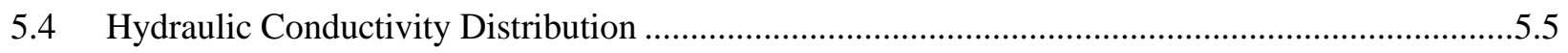

5.5 Post-Hanford Operations, Steady-State Potentiometric Surface for SGM, and Streamtrace Along Peak Concentration Pathways .....................................................................................

5.6 BTCs Simulated by CFEST Site-Wide Model for T-Farm Case 1 ..............................................5.9 
5.7 Composite SGM Results for Case 1 for the East Flow Path......................................................5.10

5.8 Composite SGM Results for Case 1 for the North Flow Path ...................................................5.11

5.9 BTCs Simulated by CFEST Model for TX-Farm Case 1 for East and North Flow Paths.............5.13

5.10 Composite SGM Results for Case 1, TX Tank Farm, for East Flow Path...................................5.14

5.11 Composite SGM Results for Case 1, TX Tank Farm, for the North Flow Path ..........................5.15 


\section{Tables}

3.1 Time Estimates for Interim and Closure Barriers at the T and TX-TY Tank Farms

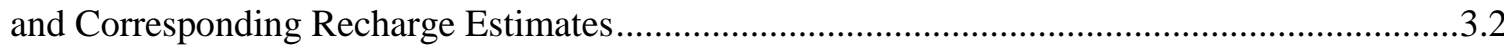

3.2 Composite van Genuchten-Mualem Parameters for Various Strata at the T and

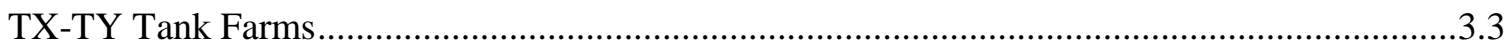

3.3 Macroscopic Anisotropy Parameters Based on the Polmann Equations for Strata at

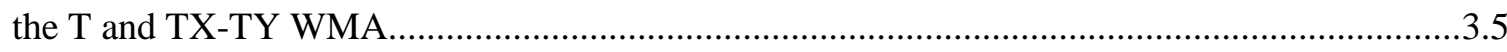

3.4 Effective Parameter Estimates for the Product of Bulk Density and Retardation

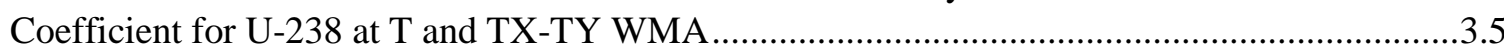

3.5 Nonreactive Macrodispersivity Estimates for Strata at T and TX-TY WMA............................3.6

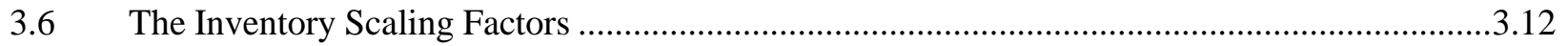

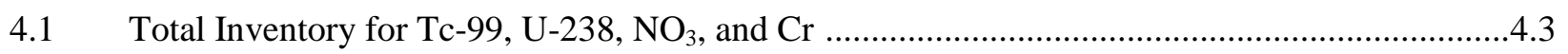

4.2 Mean Aqueous-Phase Saturation....................................................................................13

4.3 Peak Concentrations and Arrival Times at the Fenceline for Case 1 ........................................14

4.4 Peak Concentrations and Arrival Times at the Fenceline for Case 2 ......................................4.15

4.5 Peak Concentrations and Arrival Times at the Fenceline for Case 3 ......................................4.17

4.6 Peak Concentrations and Arrival Times at the Fenceline for Case 4 ........................................4.19

4.7 Peak Concentrations and Arrival Times at the WMA Fenceline for Case 5 ............................4.21

4.8 Peak Concentrations and Arrival Times at the WMA Fenceline for Case 6............................4.22

4.9 Peak Concentrations and Arrival Times at the WMA Fenceline for Case 7 .............................4.23

4.10 Peak Concentrations and Arrival Times at the WMA Fenceline for Case 8 ............................4.24

4.11 Predicted Peak Tc-99 Flux, Arrival Time, and Cumulative Mass ..........................................4.26

4.12 Predicted Peak U-238 Flux, Arrival Time, and Cumulative Mass..............................................4.27

4.13 Predicted Peak $\mathrm{NO}_{3}$ Flux, Arrival Time, and Cumulative Mass ...............................................4.27

4.14 Predicted Peak Cr Flux, Arrival Time, and Cumulative Mass .................................................4.28

4.15 Predicted Peak Tc-99 Aqueous Concentrations and Arrival Time Summary ...........................4.29

4.16 Predicted Peak U-238 Aqueous Concentrations and Arrival Time Summary ..........................4.30

4.17 Predicted Peak $\mathrm{NO}_{3}$ Aqueous Concentrations and Arrival Time Summary .............................4.31

4.18 Predicted Peak Cr Aqueous Concentrations and Arrival Time Summary .................................4.32

4.19 STOMP Mass Balance Within the 2-D Slice for Tc-99 .............................................................33

4.20 STOMP Mass Balance Within the 2-D Slice for U-238 ….......................................................33

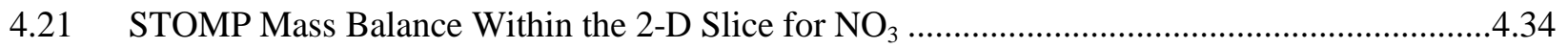

4.22 STOMP Mass Balance Within the 2-D Slice for $\mathrm{Cr}$.............................................................4.34

5.1 Travel Distances, Times, and Average Velocities for Streamtube Model at T Farm...................5.7

5.2 Travel Distances, Times, and Average Velocities for Streamtube Model at TX Farm.................5.7

5.3 Peak Tc-99 Concentrations at the 200 West Eastern Boundary, Exclusion Boundary, and Columbia River for Case 1, T Tank Farm ... 
5.4 Peak Tc-99 Concentrations at the 200 West Eastern Boundary, Exclusion Boundary,

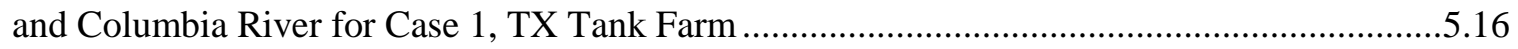

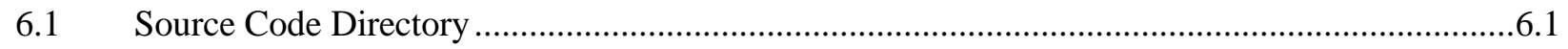

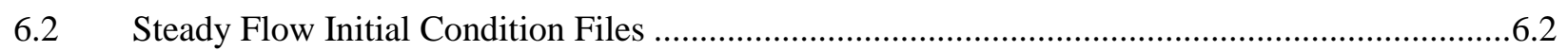

6.3 Coupled Vadose Zone and Unconfined Aquifer Modeling Files .............................................6.3

6.4 Analytical Groundwater Transport Modeling Files .............................................................6.4 